W.A. Tweed MD FRCPC, ${ }^{*}$ R. Amatya MBBS DA(UK), $\dagger$

T.M. Tuladhar MBBS FFARCS, $\uparrow$

J.R. Maltby MB FFARCS FRCPC,

C.K. Gurung MSc, $\S$ T.J. McCaughey MB FRCPC

\title{
Anaesthesia services and the education of anaesthetists in Nepal: a model for sustainable development?
}

In 1985 the University of Calgary in Canada and Tribhuvan University in Kathmandu, Nepal jointly established the Diploma in Anaesthesiology (DA) programme in Nepal. To evaluate the impact of the DA Programme and provide a data base for long-term planning we conducted a national survey in 1992. We sought to describe anaesthesia manpower and workloads, and to make an inventory of facilities, equipment, and supplies in different sized hospitals. Twenty-seven hospitals providing surgical services were included, nine inside and 18 outside the Kathmandu valley. Seventeen of the 21 respondent hospitals had at least one specialist anaesthetist. The results identify both strengths and weaknesses in Nepal's anaesthesia services and provide important guidelines for planning. When the DA course was launched there were only seven specialist anaesthetists in Nepal. The shortage of anaesthetists was an important factor limiting surgical services, and after DA graduates were posted to zonal ( 50 bed) and regional (150-200 bed) hospitals the surgical case loads doubled. There are now about 40 specialist anaesthetists in the country, of which half are DA graduates, but many hospitals have only one anaesthetist. That isolation, plus lack of continuing education (CME), are im-

\section{Key words}

ANAESTHESIA: equipment;

EDUCATION: continuing, residents;

EQUIPMENT: anaesthesia machines;

ORGANIZATIONS: Society of Anaesthesiologists of Nepal,

World Federation of Societies of Anaesthesiologists.

From the Department of Anaesthesia, *Health Sciences Centre, Winnipeg, Manitoba; †Tribhuvan University Teaching Hospital and Bir Hospital, Kathmandu, Nepal; $¥$ Foothills Hospital and the University of Calgary, Alberta; IShawville Hospital, Quebec; §Department of Community Medicine, Tribhuvan University Institute of Medicine, Kathmandu, Nepal.

Address correspondence to: Dr. J.R. Maltby, Department of Anaesthesia, Foothills Hospital, 1403-29 Street N.W., Calgary, Alberta, Canada T2N 2T9.

Accepted for publication 30th June, 1993. portant factors threatening quality of care. Recognizing the singular role of the DA programme in alleviating Nepal's shortage of anaesthetists, we conclude that it should be renewed and strengthened to meet the needs of the next decade. Techniques commonly used at the zonal level: regional, draw-over, and total IV anaesthesia, should be stressed. At the same time fresh initiatives are required in CME and higher education for the renewal of teaching staff. Serious deficiencies and maldistribution of equipment, supplies and drugs were found, with considerably poorer inventories in smaller- and intermediatesized hospitals. To accommodate better the chronic shortages of anaesthetic gases and scarcity of reliable anaesthetic machines in hospitals of that size, we conclude that they should not attempt to stock $\mathrm{N}_{2} \mathrm{O}$. Using air- $\mathrm{O}_{2}$ for all inhalational anaesthesia would streamline equipment needs, reduce the risks of hypoxia, and simplify training. Since much equipment, even of relatively recent acquisition, was unserviceable, establishment of regional repair and maintenance centres and training of service technicians are urgent needs. Lastly we believe that the community of professional anaesthetists, through their Society, must play a pivotal role in determining standards of practice of anaesthetists and developing innovative means to maintain communications and disseminate CME

En 1985, luniversité de Calgary au Canada et celle de Tribhuvan de Katmandou s'unissaient pour créer un diplôme de compétence en anesthésiologie (DA) au Népal. Pour l'évaluer l'impact de ce programme et pour constituer une banque de données destinées à la planification à long terme, nous avons fait une enquête nationale en 1992. Nous avons essayé de déterminer les effectifs et la charge de travail et de créer un inventaire des structures hospitalières de l'équipement et du matériel dhôpitaux de différentes importances. Vingt-sept hôpitaux chirurgicaux ont été inclus dont neuf de la vallée de Katmandou et 18 situés en dehors de celle-ci. Dix-sept des 21 hôpitaux qui ont collaboré à l'étude avaient au moins un spécialiste en anesthésie. Les résultats permettent didentifier à la fois les points forts et les points faibles des services anesthésiques $d u$ Népal et de fournir des lignes de conduite essentielles pour la planification. Quand le cours de DA a été mis sur pied, le 
Népal ne comptail que 17 anesthésistes. Cette pénurie était un facteur limitatif important pour les services chirurgicaux. Par la suite, les possesseurs du DA ont été placés dans des hôpitaux de zone (50 lits) et de régions (150-200 lits), ce qui a permis de doubler le nombre d'interventions chirurgicales. Environ quarante anesthésistes exercent maintenant dans le pays, dont la moitiés sont des diplômés du DA, mais plusieurs hôpitaux n'ont qu'un seul anesthésiste. Cet isolement associé à l'absence de formation continue sont des facteurs qui menacent la qualité des soins. Tout en reconnaissant le rôle particulier du programme de DA pour le soulagement de la pénurie d'anesthésiste au Népal, nous concluons qu'll devrait être répété et amélioré pour rencontrer les besoins de la prochaine décennie. La régionale et l'anesthésie intraveineuse intégrale devraient être les techniques préconisées dans les hôpitaux de zones. En même temps, on devrait fovoriser l'éducation médicale continue et une formation de niveau plus élevé pour le personnel enseignant. Des pénuries et une mauvaise distribution du matériel, fournitures et médicaments ont été identifiées dans les hôpitaux intermédiaires et plus petits. Pour faire face au manque chronique de gaz anesthésique et à la rareté des appareils d'anesthésie utilisables dans ces hôpitaux, nous concluons quil est inutile de tenter de stocker du $\mathrm{N}_{2} \mathrm{O}$. Lutilisation d'air- $\mathrm{O}_{2}$ pour l'anesthésie inhalatoire diminuerait le besoin d'équipement, réduirait le risque dhypoxie, et simplifierait la formation. Comme beaucoup de ces appareils, même les plus récents, sont mal entretenus, il faut établir en toute urgence des centres d'entretien régionaux et former des techniciens. Finalement, nous croyons que la communauté des anesthésistes, grâce à leurs associations, doit jouer un rôle primordial dans l'établissement des normes d'exercice et créer des moyens de communication favorables à l'éducation médicale continue.

In 1985 the University of Calgary in Canada and Tribhuvan University (TU) in Nepal established a joint anaesthesia training programme in Nepal. ' A progress report published in $1991^{2}$ documented growth in several areas: training of anaesthetists who stayed to practise in Nepal, appointment of trained anaesthetists to hospitals outside the Kathmandu Valley, the establishment of an annual Anaesthesiology Symposium, the formation of the Society of Anaesthesiologists of Nepal and its acceptance as a member of the World Federation of Societies of Anaesthesiologists (WFSA).

This survey was conducted in 1992 to acquire a data base for long-term planning. We sought to describe the distribution and qualifications of anaesthetic manpower in Nepal, to assess anaesthesia workloads, and to make an inventory of anaesthesia equipment, supplies and drugs in different sized hospitals. The results point out critical deficiencies in anaesthesia resources and provide important guidelines for national planning. We are re- porting these results because we believe that they apply not only to Nepal, but also to other countries which are in a similar state of development. This information will be useful to all those who provide aid and train anaesthetists for international development of our specialty. In addition we describe a methodology for objective comparison of anaesthesia resources among hospitals of different size and geographic location within a country, or among different developing countries.

\section{Background}

Nepal is a small over-populated country lying between the Gangetic plain and the peaks of the Himalayas. A large proportion of the roughly 20 million Nepalese live in isolated mountain valleys and exist on subsistence level agriculture. Kathmandu, the capital and centre of government, lies in a fertile and temperate valley which is home to over two million people. In much of the country the medical care is primitive, as attested by an infant mortality rate of 193 and a maternal mortality rate of 13.5 per thousand live births. ${ }^{3,4}$ For Nepal as a whole, there is approximately one hospital bed per 4000 people and one doctor per 16000 . The Ministry of Health budget is only three percent of the total national budget, or US\$ 1.84 per capita per annum. ${ }^{5}$

In 1985 there were seven specialist anaesthetists* working in Nepal, all in the Kathmandu valley. That year the one year Diploma in Anaesthesiology (DA) programme was established and each year since, with the assistance of a Canadian preceptor, four or five physician anaesthetists have graduated from the course. In 1989 a preliminary survey was carried out to determine the distribution of the DA programme graduates and the type of practice of those who had been appointed to the zonal and regional hospitals $\dagger$ of Nepal. Those results convinced us that a more comprehensive survey was required to encompass all hospitals providing surgical services in Nepal. The data in this report were collected in 1992.

\section{Methods}

Preliminary information pertaining to hospitals and medical manpower was provided by the Ministry of Health (MOH) of His Majesty's Government (HMG). Based on that information, a survey of all hospitals with more than 50 beds which provided surgical services was undertaken. No hospital of less than 50 beds was regularly providing

* A specialist anaesthetist is defined as a medical graduate with a postgraduate qualification in anaesthesia, i.e., FFARCS, FRCAnaes, DA, MD(Anaes).

†Both zonal and regional hospitals provide surgical services. Zonal hospitals have about 50 beds, regional hospitals 50-150 beds. 
TABLE I Operating facilities and support services in the respondent hospitals

\begin{tabular}{llllll}
\hline Size & $\begin{array}{l}\text { Number } \\
\text { of } \\
\text { (beds) }\end{array}$ & $\begin{array}{l}\text { Modal } \\
\text { ho. of } \\
\text { hot }\end{array}$ & $\begin{array}{l}\text { Modal } \\
\text { no. of } \\
\text { LR }\end{array}$ & $\begin{array}{l}\text { Lab. } \\
\text { facility }\end{array}$ & $\begin{array}{l}\text { Blood } \\
\text { bank }\end{array}$ \\
\hline $50-100$ & 7 & 1 & 1 & $6(86 \%)$ & $3(43 \%)$ \\
$101-200$ & 8 & 2 & 1 & $8(100 \%)$ & $6(75 \%)$ \\
$200+$ & 6 & 3 & 1 & $5(83 \%)$ & $5(83 \%)$ \\
\hline
\end{tabular}

* Modal number of operating theatres for each level of hospital.

† Modal number of labour rooms for each level of hospital.

Two of the eye hospitals had no laboratory facilities and four had no $x$-ray or blood banks. All other hospitals had $x$-ray facilities, though not all were serviceable.

a surgical service and five hospitals with more than 50 beds were excluded because their focus (tuberculosis, leprosy) was non-surgical. Each hospital received three questionnaires: one for the operating theatre (OT) supervisor, one for the hospital director and one for the anaesthetist(s).* The principal investigators pretested the survey instruments by visiting selected zonal hospitals and filling in the draft questionnaires during detailed interviews with the target respondents. The final questionnaires were then mailed or personally delivered to each of the target hospitals. Follow-up inquiries or visits were made to encourage completion of the forms. When all the data was tabulated a one-day workshop was held to discuss the results and develop recommendations.

Twenty-seven hospitals met the inclusion criteria, nine within and 18 outside the Kathmandu valley. These included four eye hospitals with no anaesthesia posts in which all surgery was done under local anaesthesia. Bed capacity ranged from 50 to 325 , with an average of 116 . For comparative analysis the hospitals were divided into three groups according to bed capacity (see Table I). All the hospitals of more than 200 beds and $53 \%$ of the total beds were within the Valley.

Twenty-one sets of completed questionnaires were finally received (response rate $78 \%$ ). These form the data base for descriptive analysis and tabulation, which were done by the Department of Community Medicine, Tribhuvan University. One-way analysis of variance (ANOVA) was used to compare the three groups of hospitals.

To assess the adequacy of the anaesthesia equipment inventory in hospitals of each group a list of 16 equipment items was generated (Appendix A). The availability or non-availability of each item in each hospital was

* Copies of these questionnaires can be obtained by writing to Professor R. Amatya, Health Development Project, TU Teaching Hospital, P.O. Box 1535, Kathmandu, Nepal.
TABLE II

\begin{tabular}{lcccc}
\hline $\begin{array}{l}\text { Size } \\
\text { (beds) }\end{array}$ & $\begin{array}{l}\text { Surgeons } \\
\text { all spec. }\end{array}$ & $\begin{array}{l}\text { Specialist } \\
\text { anaesth. }\end{array}$ & $\begin{array}{l}\text { Untrained } \\
\text { anaesthetic } \\
\text { MO }\end{array}$ & $\begin{array}{l}\text { Anaesth. } \\
\text { nurse and } \\
\text { assistant }\end{array}$ \\
\hline $50-100$ & 10 & 4 & 1 & 1 \\
$101-200$ & 25 & 7 & 5 & 11 \\
$200+$ & $\frac{107}{142}$ & $\underline{21}$ & $\underline{11}$ & $\frac{26}{7}$ \\
Total & $\frac{11}{32}$ & $\frac{7}{38}$ \\
\hline
\end{tabular}

noted, as well as the number of each, and the number in working order. An index to estimate the average availability of the listed equipment in each group of hospitals was calculated as follows:

Availability Index, $I=\Sigma\left(n_{i} / N\right) \div x$

Where $n_{i}$ is the number of hospitals in that group in which that item (i) of equipment was available, $x$ is the total number of items on the list, and $N$ is the number of hospitals in the group. The four eye hospitals, which had no posted anaesthetists and no anaesthesia equipment, were excluded from this analysis. The index $(I)$ is the probability of finding any given item of equipment in the stock of a hospital of that group. Since $I$ is normalized for differences in the size $(N)$ of each group, it allows valid comparisons among groups of hospitals.

Lists of essential and useful supplies, drugs and anaesthetic agents were also drawn up (see Appendices B and $C$ ), and their availability was estimated in a similar manner.

\section{Results}

Operating rooms and support services in the 21 respondent hospitals are shown in Table I.

Table II compares surgical and anaesthetic manpower. The ratio of specialist anaesthetists to surgeons was about 1:5, and the same ratio was derived from statistics provided by the MOH in Kathmandu. ${ }^{6}$ There were no hospitals in which untrained anaesthetic medical officers (MOs) were working independently. However, in many hospitals MOs were essentially substituting for specialists, and in larger hospitals were providing the same service as residents or registrars. There were only a few hospitals where nurses were administering anaesthetics; ${ }^{7}$ in most they acted as anaesthetic assistants. Overall, $86 \%$ of the sanctioned posts in surgery and $78 \%$ of the specialist posts in anaesthesia were filled. This was about the same for other specialists, generalist physicians, and nurses.

Anaesthetic case loads and case acuity for different sizes of hospital are shown in Table III. At all levels emergency work constituted a large proportion (25-28\%) of the total practice. If the monthly figures are extrap- 
TABLE III Average monthly anaesthetic case load by hospital size

\begin{tabular}{lrrrl}
\hline $\begin{array}{l}\text { Size } \\
\text { (beds) }\end{array}$ & Elective & Emergency & C-section & Total \\
\hline $50-100$ & $87(68 \%)$ & $32(25 \%)$ & $9(7 \%)$ & $128(100 \%)$ \\
$101-200$ & $185(65 \%)$ & $80(28 \%)$ & $18(6 \%)$ & $283(100 \%)$ \\
$200+$ & $267(61 \%)$ & $112(26 \%)$ & $56(13 \%)$ & $435(100 \%)$ \\
\hline
\end{tabular}

If the monthly figures are extrapolated the average case loads per annum are about $1540,3400,5240$ for the three levels.

TABLE IV Methods of anaesthesia

\begin{tabular}{lllll}
\hline & Inhalation & Regiona* & Local & Intravenous $\neq$ \\
\hline $\begin{array}{l}\text { Elective cases } \\
\begin{array}{l}\text { Emergency } \\
\text { cases }\end{array}\end{array}$ & $42 \%$ & $11 \%$ & $28 \%$ & $19 \%$ \\
\hline
\end{tabular}

*Includes spinal, epidural, caudal, and nerve blocks.

$\dagger$ Local infiltration anaesthesia.

$\ddagger$ Total intravenous general anaesthesia, usually with ketamine as the primary agent.

olated the average case loads per annum are about 1540 , 3400,5240 for the three levels.

Table IV shows the anaesthetic techniques commonly used. Almost a third of both elective and emergency cases were done with local infiltration, generally administered by the surgeon. This reflects the high proportions, $53 \%$ and $48 \%$ respectively, that were classed as minor operations. For inhalation anaesthesia the main agents were halothane and ether; nitrous oxide was not generally available outside the Kathmandu valley. Of particular interest was the large number of cases done with total intravenous anaesthesia, primarily ketamine. This technique is now rarely practiced or taught in developed countries, although widely used elsewhere.

No hospital had a complete inventory of equipment as defined by our list, but the larger hospitals were significantly better equipped than those of intermediate and smaller size. The indices of average availability (see Methods) for the three groups of hospitals, in descending order of size, were $0.71,0.51$, and $0.41(P<0.05)$. However, many items of equipment were not in working order. For example 38 anaesthesia machines in 12 hospitals were found to be in working order, but 16 others were not.

A similar mal-distribution was found with respect to reusable supplies. The indices for the three groups, again in descending order, were $0.97,0.74$, and $0.63(P<$ $0.001)$. For the complete list of 27 essential and useful drugs the indices for "always available" were $0.75,0.64$, and $0.50(P<0.05)$. Although availability was better for the abbreviated list of 15 "essential" drugs (see Table V), the smaller hospitals were still not as well stocked.
TABLE V Indices of average availability of equipment, supplies and drugs

\begin{tabular}{lllll}
\hline $\begin{array}{l}\text { Size } \\
\text { (beds) }\end{array}$ & Equipment* & $\begin{array}{l}\text { Reusable } \\
\text { supplies } \dagger\end{array}$ & $\begin{array}{l}\text { Anaesthetic } \\
\text { drugs }\end{array}$ & $\begin{array}{l}\text { Essential } \\
\text { drugs } \dagger\end{array}$ \\
\hline $50-100$ & 0.41 & 0.63 & 0.50 & 0.65 \\
$101-200$ & 0.51 & 0.74 & 0.64 & 0.86 \\
$200+$ & 0.71 & 0.97 & 0.75 & 0.92 \\
\hline
\end{tabular}

The definition and formula for calculating average availability are given in the Methods. For lists of equipment, reusable equipment, reusable supplies, anaesthetic agents and drugs see the Appendices.

Essential drugs are the starred items in Appendix C. The index $(I)$ is the probability of finding any given item from a list in the stock of a hospital of that size group.

$* P<0.05$ by ANOVA.

$\dagger P<0.01$ by ANOVA.

TABLE VI Indicators of quality care

\begin{tabular}{lrl}
\hline & Yes & Respondents \\
\hline Pre-anaesthetic visit & & \\
- Elective cases & $15(88 \%)$ & 17 \\
- Emerg. cases & $12(71 \%)$ & 17 \\
Anaesthetic record & $10(59 \%)$ & 17 \\
Consultations outside OT & $15(88 \%)$ & 17 \\
Assistants available during anaesthesia & & \\
- MO & $7(41 \%)$ & \\
- Nurse & $11(65 \%)$ & \\
- Paramedic & $10(59 \%)$ & \\
Library available & $13(76 \%)$ & 17 \\
Journals available & $8(47 \%)$ & 17 \\
Case discussions & $9(53 \%)$ & 17 \\
Staff meetings & $9(53 \%)$ & 17 \\
Replacement available & $10(59 \%)$ & 17 \\
\hline
\end{tabular}

It is of particular importance to note that oxygen was always available in only $70 \%$ of hospitals and nitrous oxide in only $35 \%$. Halothane was available in $70 \%$ and ether in $88 \%$.

Table VI is drawn from the responses of the specialist anaesthetists in 17 hospitals and lists a number of factors that are loosely grouped as indicators of quality of care. The first two, in particular, are universally accepted as such. Although six who did not maintain complete anaesthetic records claimed to keep short descriptions, two kept no records. The requests for consultations demonstrate that anaesthetists' services outside the OT were valued by other physicians. In most hospitals assistants were available during the administration of anaesthesia, but $40 \%$ of respondents had no replacement if they left for vacation or CME. Only with the Kathmandu valley did manpower allow replacement by a specialist anaesthetist; outside the Valley it was by MOs, nurses, or paramedics. Lack of opportunity for CME was cited equally by an- 
aesthetists inside and outside of the Valley. Up-to-date texts, journals, and case discussions were equally unavailable to both groups.

Finally, the majority of hospital directors stated that, although their surgical facilities were generally inadequate (78\%), anaesthesia services had improved over the past five years (76\%). In comparison to the previous survey conducted in $1989^{2}$ surgical workloads have doubled, although it is not clear whether the case mix has changed.

\section{Discussion}

The data we have reported were derived from retrospective reviews of surgical and anaesthetic records, inventory counts and open-ended questions. Using pre-defined lists for equipment, supplies and drugs, and a summary statistic $(I)$, we have been able to compare objectively different groups of hospitals, both on the basis of hospital size and geographic location. Provided the same lists were used, this method could be employed by others, either to examine the distribution of anaesthesia resources within a country or to make international comparisons. Obviously the items on the lists would not lead to valid comparisons between highly developed and underdeveloped countries.

This survey has not identified all sites in Nepal where anaesthetic services are required, but we believe we have sampled the major providers. The $78 \%$ response rate gives us confidence in the validity of the sample. Six nonresponders were one eye hospital, one district hospital, and four zonal hospitals, of which the majority did not have a posted anaesthetist. The occasional emergency operation is performed in hospitals of less than 50 beds but we have only anecdotal information about those cases. Within the larger centres, particularly Kathmandu, there is also a nascent but expanding private service, utilizing small private "nursing homes." We have not attempted to assess the impact of this practice although it may have important implications for future manpower planning.

The existing surgical services are deficient relative to both the size of the country and the burden of surgically treatable disease, and even these services are inaccessible to the bulk of the population. Though our crude measures indicate that the basic requirements of operating theatres, laboratory and $x$-ray facilities, and blood banks were available in the majority of the hospitals sampled, there was almost unanimous agreement that the facilities were inadequate. However, our task was not to evaluate the surgical care, but to examine the adequacy of anaesthesia services relative to the existing demands. This will be discussed under the headings of anaesthetic manpower, education of anaesthetists, equipment and supplies, and standards of practice.

\section{Anaesthetic manpower}

Despite the gratifying increase in the number of specialist anaesthetists in Nepal since 1985, from seven to nearly $40,{ }^{*}$ the survey indicates that the specialty is still seriously understaffed. The ratio of anaesthetists to surgeons was 1:5, smaller than that of the U.K. $(1: 2.5)^{8}$ and Canada (1:3). ${ }^{9}$ However, if specialists and anaesthetic MOs are combined the ratio is $1: 3$, indicating that the problem is with training rather than the number of available physicians. Many hospitals had only one posted anaesthetist with no provision for a replacement if he was away. In the smaller hospitals untrained MOs and nurses were substituting for specialists, and in the larger hospitals MOs, although not considered anaesthesia trainees, were acting as residents and registrars. Comparing this survey with that of 1989 confirms that the surgical workloads have approximately doubled. The increase in reliable anaesthesia services is at least partly responsible, and it is evident that long-term planning must include provisions for further increases in workloads as well as attrition due to retirement. In addition, the new ventures in private practice are enticing senior anaesthetists away from HMG and teaching hospitals. It is therefore reasonable to predict that the present output of four or five graduates per year by the DA programme will be required for several more years, and perhaps indefinitely.

\section{Training and education}

The joint educational experiment initiated in 1985 has proved highly successful. Currently $80 \%$ of the DA programme graduates are practicing in Nepal and they constitute more than half of the total specialists. This survey points out two areas where further improvements in anaesthesia education are needed. First, the DA programme should stress the anaesthetic techniques that are commonly used in the intermediate and smaller hospitals, such as regional anaesthesia, total intravenous anaesthesia, and draw-over techniques. Second, pragmatic solutions to the problem of continuing education are urgently needed. These could be addressed by a joint endeavour between the Institute of Medicine and the Society of Anaesthesiologists of Nepal. Since sending doctors abroad for higher education before 1985 did not solve the country's manpower needs, we conclude that the Institute of Medicine and the MOH must develop longterm plans to ensure the stability and quality of the DA programme. Although the question of higher education was not part of the survey, during the workshop it became evident that it would be necessary to consider means by which individuals appointed to positions in the teaching

*The estimate of current manpower was provided by the Society of Anaesthesiologists of Nepal. 
hospitals could achieve higher professional qualifications. It was suggested that higher education could be based on the DA model, that is a joint venture at the MD* level between TU and a teaching institution in another country.

\section{Equipment and supplies}

Problems related to equipment and supplies involve several related issues: procurement, distribution, inventory control, and maintenance. Since each hospital is responsible for its own procurement, each has its own unique blend of donated, borrowed, or inherited apparatus. Of particular concern was the almost complete lack of servicing and repair facilities, even in the major centres. Thus, though sophisticated equipment has been contributed by well-meaning donors, it is often unused because of simple malfunctions. The skewed distribution of all items of inventory among different sized hospitals, which equates with hospitals within or outside the Kathmandu valley, was striking. Although this was empirically evident to the investigators, the statistical analysis emphasizes the differences. The heterogeneity among hospitals of similar size was also apparent and many hospitals did not have reliable supplies of essential drugs, oxygen or nitrous oxide.

Because of the cost and limited availability of nitrous oxide we conclude that intermediate and stmaller sized hospitals should not attempt to stock it. This is in agreement with WHO and WFSA recommendations ${ }^{10}$ and would have implications for the choice of anaesthetic equipment and for DA training, but would have little impact on the quality of anaesthetic practice in these hospitals. In fact the elimination of nitrous oxide would greatly reduce the risk of hypoxic accidents and simplify equipment requirements by eliminating the need for oxygen analyzers and fail-safe devices.

We see an immediate need to develop and maintain standards for equipment and for inventories of essential supplies and drugs. Of equal urgency is the establishment of regional repair centres and training of repair technicians. Some donors should be advised that their equipment will be accepted only if it is accompanied by a stock of spare parts, a maintenance contract and provision to train a maintenance technician. Each department of anaesthesia should train a technician who is responsible for maintaining the inventory, as well as repairs and servicing of equipment.

\section{Quality of care}

The survey results, particularly Table VI, point out problems in the broad area of quality of care, and warn that

*In Nepal, MB BS is the basic medical qualification. MD is a higher degree that requires three years of postgraduate training. issues of quality assurance and standards of practice must be addressed. The WFSA has recently approved international guidelines for standards of practice, " and implementation of those guidelines should be given high priority. We see the Society of Anaesthesiologists of Nepal, in cooperation with the MOH and hospital directors, playing a leading role. We also view the problems of $\mathrm{CME}$, anaesthetic work loads and conditions of practice as integral aspects of quality assurance, and they also require joint action.

This survey has provided, for the first time, a valid data base on which to plan anaesthetic services for Nepal. Although considerable progress has been made in seven years, and a firm basis for the specialty of anaesthesia has been established, a great deal still needs to be done. As a first step, a proposal is being prepared by anaesthetists at the two major teaching hospitals in Kathmandu to standardize anaesthesia equipment in the zonal and regional hospitals. Continued development of the specialty will require joint commitment and action from all the agencies with a stake in Nepal's health care: the $\mathrm{MOH}$, the Institute of Medicine of the university, the TU Teaching Hospital, hospital boards and directors, and foreign partners. Lastly, if the specialty is to develop in a professional manner, anaesthetists themselves must play a pivotal role, particularly through their recently established national society.

\section{Acknowledgments}

The authors want to express their thanks to the WHO for providing the funds for this project.
Appendix A
1 Anaesthesia machine
2 EMO ether vaporizer
3 Oxford Miniature Vaporizer (OMV)
4 Other vaporizer
5 Ventilator
$6 \mathrm{ECG}$
7 Nerve stimulator
8 Pulse oximeter
9 Oxygen analyzer
10 Laryngoscope
$11 \mathrm{O}_{2}$ concentrator
$12 \mathrm{O}_{2}$ cylinder
$13 \mathrm{~N}_{2} \mathrm{O}$ cylinder
14 Flowmeter
15 Ambu bag
16 Defibrillator

\section{Appendix B}

1 Endotracheal tubes (sizes 4-9)

2 Epidural needles 
3 Epidural catheters

4 Spinal needles

\section{Appendix C}

1 Thiopentone*

2 Ketamine*

3 Diazepam*

4 Lorazepam

5 Promethazine*

6 Atropine*

7 Scopolamine

8 Metoclopramide

9 Trimeprazine

10 Droperidol

11 Fentanyl

12 Pethidine*

13 Morphine

14 Pentazocine*

15 Oxygen*

16 Nitrous oxide

17 Halothane*

18 Ether*

19 Succinylcholine*

20 Pancuronium

21 Tubocurarine

22 Gallamine*

23 Neostigmine*

24 Xylocaine $2 \% *$

25 Xylocaine $2 \%$ with adreraline

26 Xylocaine $5 \%$ hyperbaric*

27 Bupivacaine $(0.25 \%$ to $0.5 \%)$

\section{References}

1 Maltby JR, Rana NB, Amatya R, Shrestha BM. Anaesthesia training in Nepal. Can J Anaesth 1987; 34 : 51-5.

2 Maltby JR, Amatya R, Rana NB, Shrestha BM, Tuladhar TM, McCaughey TJ. Anaesthesia training and development in Nepal 1985-1990. Can J Anaesth 1991; 38: 105-10.

3 United Nations Development Program. Human Development Report, 1991.

4 Beaton $S$, Robinson $S$. Estimation of maternal mortality in the mid-western region of Nepal: use of the sisterhood method. Journal of the Nepal Medical Association 1993; 31: 45-55.

5 Pant $K D$. Financial system in health services of Nepal. Journal of the Nepal Medical Association 1992; 30: 101.

6 Ministry of Health/His Majesty's Government (Kathmandu, Nepal). Health Information Bulletin 1991, volume 7.

*Essential drugs
7 Munday DF. Evaluation of the work of nurse anaesthetists at Patan and Tansen Hospitals during the years 1989 to 1990. Journal of the Nepal Medical Association 1991; 31: 150-3.

8 Rees LT. Anaesthetic staffing in England and Wales. Anaesthesia 1980; 35: 1972-6.

9 Donen N, White IWC, Snidal L, Sanmartin C. Anaesthesia manpower requirements - which data should we use for deciding on adequate numbers of trainees and certificants? Can J Anaesth 1993; 40: A73.

10 Dobson MB. Anaesthesia at the District Hospital. Geneva: World Health Organization, 1988.

11 International standards for a safe practice of anaesthesia. Adopted by the World Federation of Societies of Anaesthesiologists, June 13, 1992. Developed by the International Task Force on Anaesthesia Safety. Anesthesia Patient Safety Foundation Newsletter, 1992; 7: 30-1. 